\title{
PELATIHAN HIDROPONIK UNTUK MENINGKATKAN KETERAMPILAN GURU-GURU PAUD
}

\author{
Ni Wayan Suardiati Putri \\ STMIK STIKOM Indonesia, Denpasar, Indonesia \\ e-mail: suardiatiputri@stiki-indonesia.ac.id \\ Kadek Suryati \\ STMIK STIKOM Indonesia, Denpasar, Indonesia \\ e-mail: kadek.suryati@stiki-indonesia.ac.id \\ Ketut Sepdyana Kartini \\ STMIK STIKOM Indonesia, Denpasar, Indonesia \\ e-mail: sepdyana@stiki-indonesia.ac.id \\ Ni Wayan Eka Wijayanti \\ STMIK STIKOM Indonesia, Denpasar, Indonesia \\ e-mail: eka.wijayanti@stiki-indonesia.ac.id \\ I Wayan Gede Wardika \\ STMIK STIKOM Indonesia, Denpasar, Indonesia \\ e-mail: iwayangedewardika@stiki-indonesia.ac.id

\section{Evi Dwi Krisna} \\ STMIK STIKOM Indonesia, Denpasar, Indonesia \\ e-mail: evidwikrisna@stiki-indonesia.ac.id
}

\begin{abstract}
From the results of discussions conducted with the Principal of the Kindergarten School. Kartika, it was agreed that the problems that were resolved in this activity were: 1) So that Partners had fun gardening media; 2) So that Partners have knowledge and skills in managing hydroponic gardens. The agreed solutions to solve the problems faced by Partners are as follows: 1) Procurement of hydroponic gardening equipment, so that gardening becomes cleaner and more attractive; 2) Training on hydroponic gardening procedures for teachers. The results of the activity showed that there was an increase in teachers' understanding of hydroponic farming by $90 \%$. Besides that, there is also an increase in teacher skills in hydroponic farming as shown by good plant growth during the harvest period.
\end{abstract}

Keywords - hydroponic training, early childhood education, gardening skills

\section{PENDAHULUAN}

Taman Kanak-kanak merupakan jenjang pendidikan anak usia dini dibawah 6 tahun dalam bentuk pendidikan formal. Pendidikan anak usia dini (PAUD) bertujuan untuk mempersiapkan anak dalam memasuki era pendidikan sekolah dasar dan mengembangkan kepribadian anak agar mampu bersosialisasi dengan lingkungan keluarga ataupun masyarakat (Putri, Suryati, Kartini, \& ..., 2020). Pembinaan dilakukan melalui pemberian rangsangan pendidikan untuk membantu pertumbuhan dan perkembangan jasmani serta 
rohani, agar anak memiliki kesiapan dalam memasuki pendidikan lebih lanjut (Kemdikbud, 2014). TK Kartika memiliki bangunan yang terdiri dari ruang kelas, ruang bermain, halaman dan kebun. Hasil wawancara dengan Kepala Sekolah TK Kartika, yaitu lbu Ni luh Nyoman Murniasih, sebagai sebuah institusi pendidikan, TK Kartika juga menyiapkan mental anak didiknya untuk dapat mengikuti jenjang pendidikan dasar selanjutnya. Kegiatan belajar mengajar adalah hal yang sangat penting untuk dilaksanakan di sekolah. Guru harus mampu menarik perhatian peserta didik untuk mendengarkan ketika sedang menjelaskan materi (Hartawan, Santika, Putri, \& I Ketut Setiawan, 2019). Dalam pelaksanaan kegiatan belajar, guru dapat melaksanakan kegiatan belajar mengajar didalam maupun diluar kelas. Pembelajaran di luar kelas menjadi lebih menyenangkan bagi anak-anak, karena mereka dapat berinteraksi secara fisik terhadap benda-benda yang dijumpai. Dan anak-anak pun tidak terasa sebenarnya mereka sudah belajar. Namun saat ini, tidak hanya fokus pada belajar tetapi juga ingin mengenalkan anak-anak pola hidup sehat dengan makan-makanan yang bergizi, salah satunya adalah sayuran. Untuk memulai membiasakan anak-anak makan sayur, mereka dapat diajak untuk bersamasama menanam sayuran. Agar kegiatan bercocok tanam menjadi lebih menarik, guru-guru akan diajarkan untuk bercocok tanam dengan teknik hidroponik. Hal ini dilakukan karena bercocok tanam dengan teknik hidroponik tidak memerlukan tanah, sehingga sayuran menjadi lebih bersih. Selain itu juga, hal ini akan sangat menarik bagi anak-anak, karena selama ini yang mereka ketahui adalah tanaman hidup jika ditanam di tanah. Dengan menggunakan teknik hidroponik proses pembelajaran akan menjadi lebih menarik dan menyenangkan. (Nurhikmahyanti, Ismawati, \& ..., 2020) juga menyatakan materi hidroponik dipilih karena hidroponik sendiri merupakan solusi bagi masyarakat untuk membudidaya sayur dan buah karena tidak memerlukan tanah sama sekali sebagai media tanaman, dan dapat dikembangkan di lahan sempit atau bahkan di dalam ruangan. Hidroponik juga memiliki keuntungan bagi lingkungan sosial karena dapat dijadikan sarana pendidikan dan pelatihan dibidang pertanian modern mulai dari kanak-kanak sampai dengan orang tua. Pada pelatihan yang dilakukan (Halim \& I, 2019) juga sependapat bahwa hidroponik tidak membutuhkan lahan atau halaman yang luas, dapat diberi nutrisi dengan mudah dan efisien, serta tidak menyebabkan polusi lingkungan. Berdasarkan uraian diatas diangkat judul pelatihan hidroponik untuk meningkatkan keterampilan guru- guru PAUD.

\section{METODE}

Kegiatan pengabdian kepada masyarakat dilaksanakan melalui pelatihan, praktikum, dan pendampingan kepada Guru PAUD TK. Kartika yang berlokasi di Desa Peguyangan Kaja, Kota Denpasar sebagai peserta pelatihan. Peserta berjumlah 10 orang yang merupakan Guru PAUD TK. Kartika. Kegiatan ini terselenggara atas dukungan dari Kampus STMIK STIKOM Indonesia yang juga dikenal dengan STIKI Indonesia melalui kegiatan Social STIKI Enggagement (SSE) 2021. Kegiatan ini merupakan bentuk kontribusi kampus terhadap penerapan keilmuan di masyarakat dengan melibatkan partisipasi Dosen dan Mahasiswa secara aktif dan berkelanjutan. Pelaksanaan kegiatan Program SSE terdiri dari beberapa tahapan yakni Pengumpulan Data, Indentifikasi Masalah, Rancangan Rencana SSE, Implementasi SSE, serta Evaluasi dan Dokumentasi. Metode pelaksanaan kegiatan SSE dilakukan dengan tahapan seperti pada Gambar 1 berikut. 


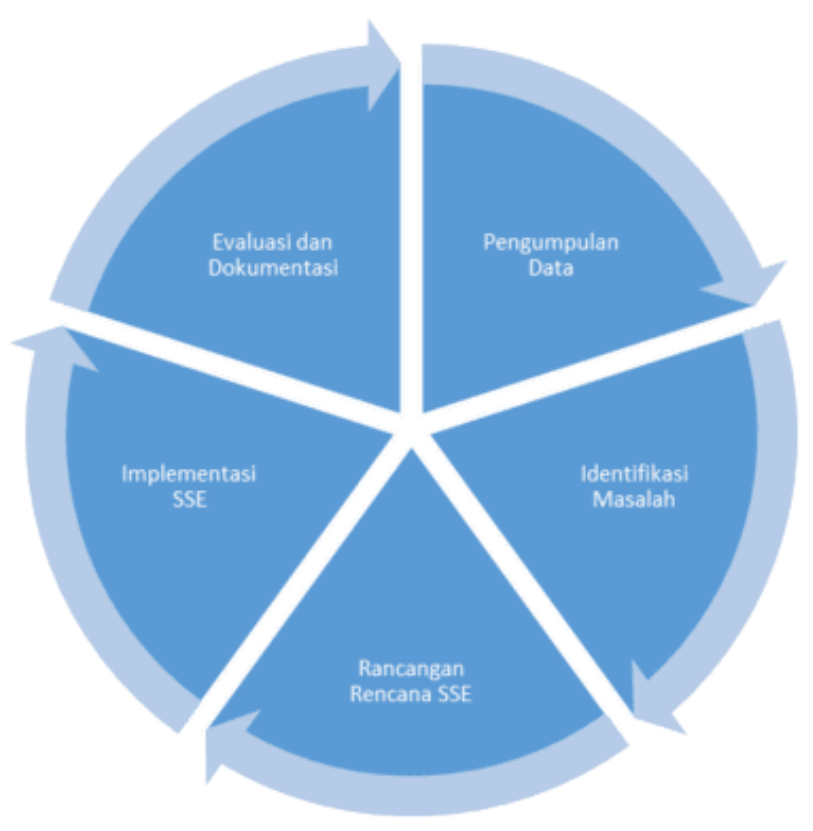

Gambar 1. Alur Pelaksanaan Kegiatan SSE

Tahapan pelaksanaan kegiatan pelatihan pada TK Kartika, meliputi:

1) Pengumpulan Data

Ini merupakan tahapan awal dalam melaksanakan kegiatan SSE di TK Kartika Peguyangan Kaja. Jenis data yang dikumpulkan adalah data primer dan data sekunder. Data primer dikumpulkan melalui teknik wawancara dengan Kepala Sekolah TK. Kartika Peguyangan Kaja. Hasil wawancara menunjukkan bahwa Sekolah memiliki kebun dengan media tanam berupa tanah. Namun jika hujan kegiatan bermain/belajar dikebun tidak bisa dilakukan karena tanah menjadi becek dan basah. Pada pengumpulan data sekunder digunakan Teknik studi literature yang bersumber dari buku, jurnal, dan website.

2) Identifikasi Masalah dan Analisi Kebutuhan

Dari hasil diskusi yang dilakukan dengan Kepala Sekolah TK. Kartika, disepakati masalah yang diselesaikan pada kegiatan SSE ini adalah:

1) Agar Mitra memiliki media berkebun yang menyenangkan;

2) Agar Mitra memiliki pengetahuan dan keterampilan dalam mengelola kebun hidroponik;

3) Rancangan Rencana SSE

Rencana SSE diawali dengan pengadaan perangkat hidroponik untuk TK Kartika Peguyangan Kaja. Selanjutkan dilaksanakan kegiatan pelatihan untuk bercocok tanam sayuran secara hidroponik. Kegiatan pelatihan diikuti dengan pendampingan selama 6 bulan mulai dari semai, perawatan, dan panen.

4) Implementasi PKM

Kegiatan ini dilakukan selama 6 bulan, yang diimplemetasikan pada TK Kartika Peguyangan Kaja.

5) Evaluasi dan Dokumentasi

Bentuk evaluasi dari kegiatan ini adalah analisis yang dilakukan peningkatan pengetahuan peserta melalui metode pre-test dan post-test. 


\section{HASIL DAN PEMBAHASAN}

\subsection{Pelaksanaan Kegiatan SSE}

Implementasi dilakukan di TK Kartika Desa Peguyangan Kaja Kecamatan Denpasar Utara Kota Denpasar. Pada kegiatan ini diberikan sebuah instalasi hidroponik yang digunakan sebagai media belajar oleh guru dalam bercocok tanam hidroponik. Hal ini dilakukan agar TK Kartika memiliki media bercocok tanam hidroponik yang dapat mendukung proses pembelajaran melalui kegiatan bercocok tanam hidroponik. Instalasi hidroponik diletakkan pada halaman terbuka sekolah sehingga memperoleh sinar matahari secara penuh. Hal ini dilakukan karena tanaman membutuhkan sinar matahari yang cukup untuk dapat tumbuh dengan baik.

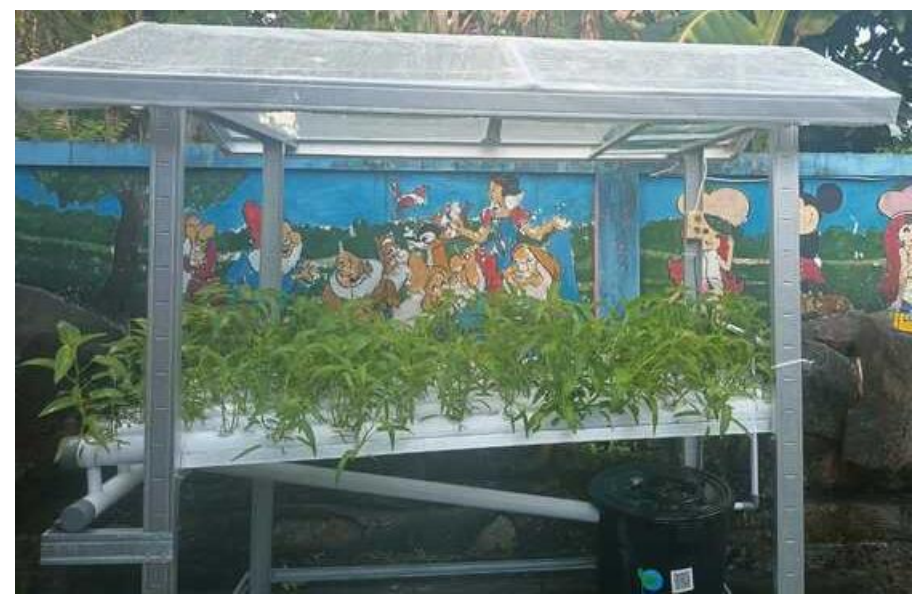

Gambar 2. Instalasi Hidroponik NFT

Gambar 2 merupakan instalasi hidroponik yang digunakan selama kegiatan berlangsung. Instalasi yang diberikan berukuan $2 \mathrm{~m} \times 1 \mathrm{~m} \times 2,3 \mathrm{~m}$ dengan model Nutrient Film Technique (NFT) yang merupakan teknik bercocok tanam hidroponik dengan membuat kemiringan pada media tanam sehingga air yang mengalir sangat kecil/tipis. Ini membuat oksigen yang dihasilkan pada media tanam menjadi lebih banyak dan baik untuk tanaman. Namun kelemahan dari metode ini adalah apabila listrik padam maka tidak ada air di dalam pipa. Model ini dipilih karena di TK. Kartika hampir tidak pernah terjadi pemadaman listrik. Instalasi ini memiliki 78 lubang tanam, tandon dengan kapasitas 80 liter, dan dilengkapi dengan atap plastik UV untuk mencegah tanaman terkena air hujan. Hal ini dilakukan karena air hujan dapat mempengaruhi konsentrasi kepekatan nutrisi dalam air. Instalasi juga dilengkapi dengan tempat semai agar benih memperoleh sinar matahari secara penuh. 


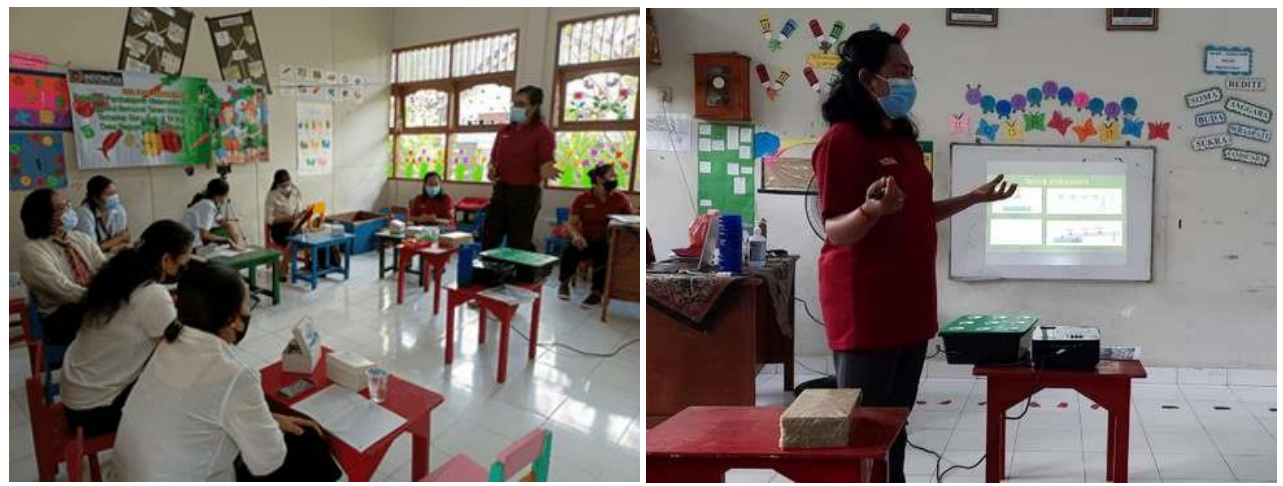

Gambar 3. Pemberian materi Hidroponik dan materi mengenai TDS meter dan $\mathrm{PH}$ air

Pada bercocok tanam hidroponik, sesuai gambar 3 diatas kegiatan diawali dengan pemberian materi terkait dengan cara bercocok tanam hidroponik dan pembekalan materi tentang TDS meter untuk mengukur kepekatan nutrisi ABmix dalam air dan juga materi mengenai $\mathrm{PH}$ meter air, kemudian dilanjutkan dengan praktik semai benih sayuran menggunakan media tanam hidroponik. Waktu penyemaian berlangsung selama 1 minggu sehingga pada pelatihan Minggu selanjutnya dilakukan praktik pindah tanam. Praktik pindah tanam merupakan kegiatan pemindahan hasil semaian dari media tanam hidroponik ke instalasi hidroponik.

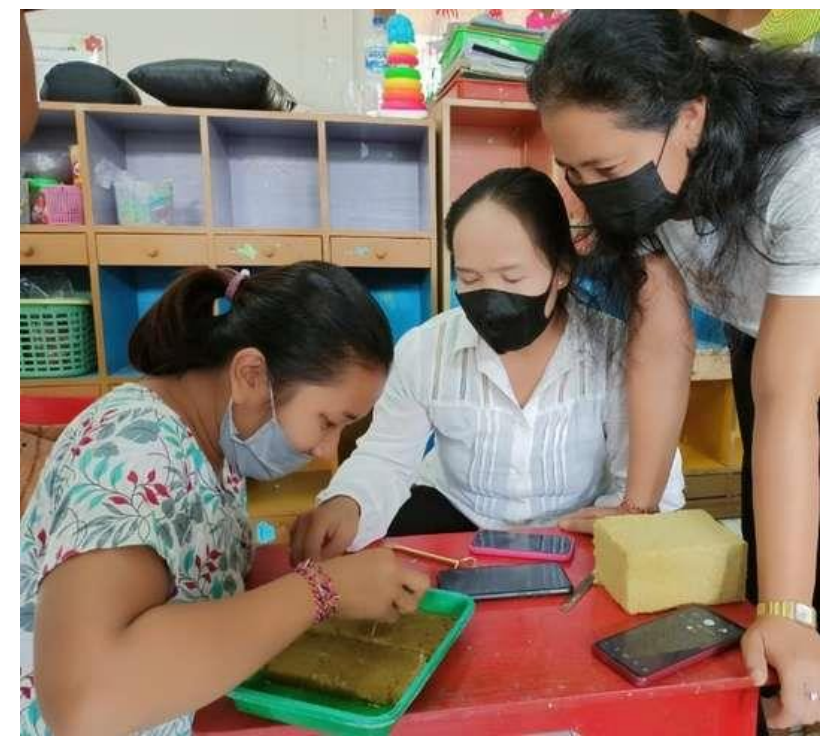

Gambar 4. Praktek penyemaian bibit sayuran

Pada Gambar 4 diatas dapat dilihat bahwa guru melakukan penyemaian bibit tanaman pada rockwall yang telah dipotong-potong sebelumnya. Penyemaian dilakukan sesuai dengan jenis tanaman yang ditanam. Bibit tanaman yang ditanam adalah kangkung, bayam merah dan bayam hijau. 


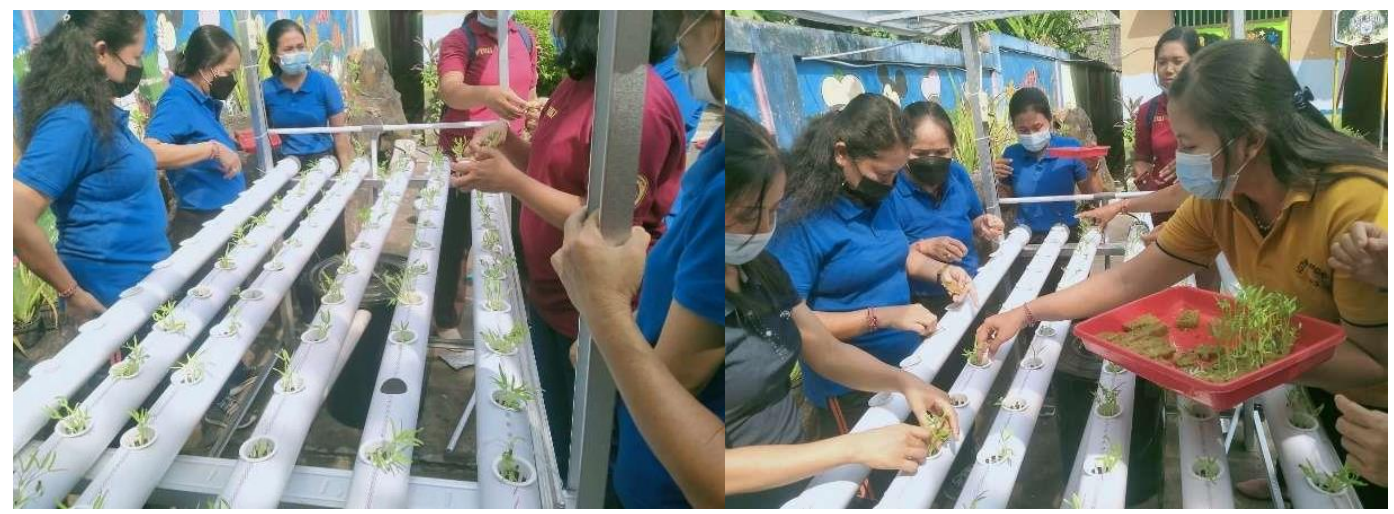

Gambar 5. Guru melakukan pindah tanam pada instalasi hidroponik

Gambar 5 diatas merupakan praktik pindah tanam yang dilakukan oleh guru. Dalam praktik pindah tanam dapat dilihat bahwa peserta sangat semangat dan antusias dalam mengikuti praktik yang diberikan. Masing-masing peserta memindahkan hasil semaian ke instalasi hidroponik yang terdapat 78 lubang tanam pada instalasi hidroponik.

\subsection{Monitoring dan Evaluasi}

Keberhasilan kegiatan dapat diketahui dengan melakukan kegiatan monitoring dan evaluasi. Kegiatan monitoring dilakukan melalui visitasi atau berkunjung ke lokasi setiap 2 minggu sekali untuk memastikan bahwa tanaman hidroponik dapat tumbuh dengan baik.

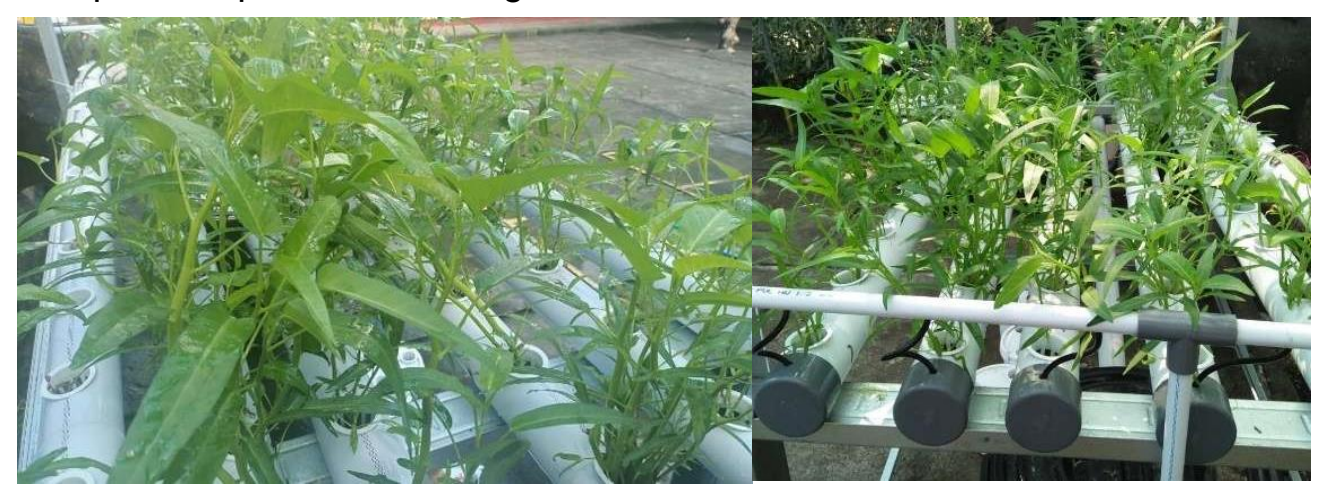

Gambar 6. Tanaman hidroponik yang tumbuh dengan baik

Pada Gambar 6 menunjukkan bahwa foto tanaman hidroponik yang diambil saat melakukan kunjungan sebagai bentuk kegiatan monitoring. Pada gambar dapat dilihat bahwa tanaman dapat tumbuh dengan baik. Instalasi diletakkan dihalaman terbuka sekolah sehingga mendapatkan pencahayaan matahari yang cukup. Disamping itu juga, listrik hidup secara terus menerus sehingga aliran air memberikan asupan nutrisi yang cukup pada tanaman. Atap plastik UV yang dipasang pada baggian atas instalasi mempu melindungi tanaman dari air hujan, namun tetap mampu ditembus oleh sinar matahari.

Disamping melakukan kunjungan, monitoring juga dilakukan secara online. Pada Gambar 6 diatas merupakan screenshoot kegiatan monitoring yang dilakukan melalui aplikasi whatsapp. Guru mengirimkan foto/video perkembangan tanaman melalui aplikasi whatsapp untuk memantau perkembangan tanaman setiap hari. Jika diperlukan adanya perawatan 
tambahan, disampaikan melalui aplikasi whatsapp, dan dipastikan kerberhasilannya ketika waktu kunjungan secara offline.

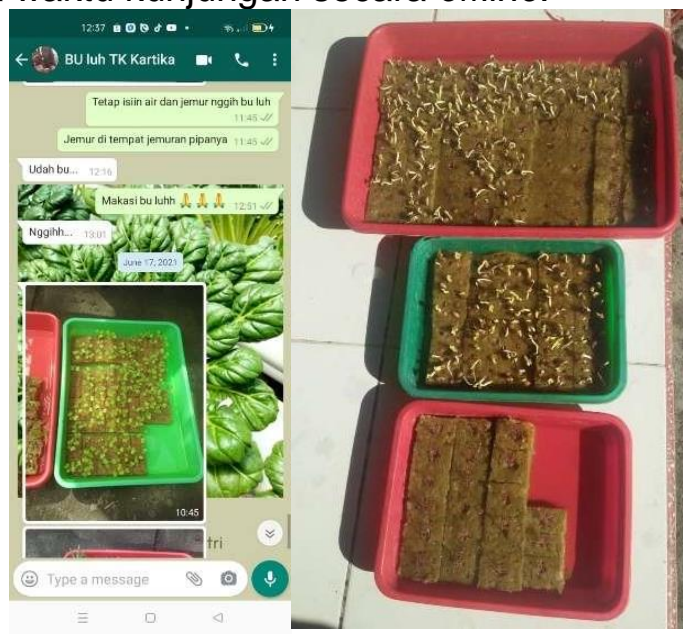

Gambar 7. Screenshot monitoring melalui aplikasi Whastapp

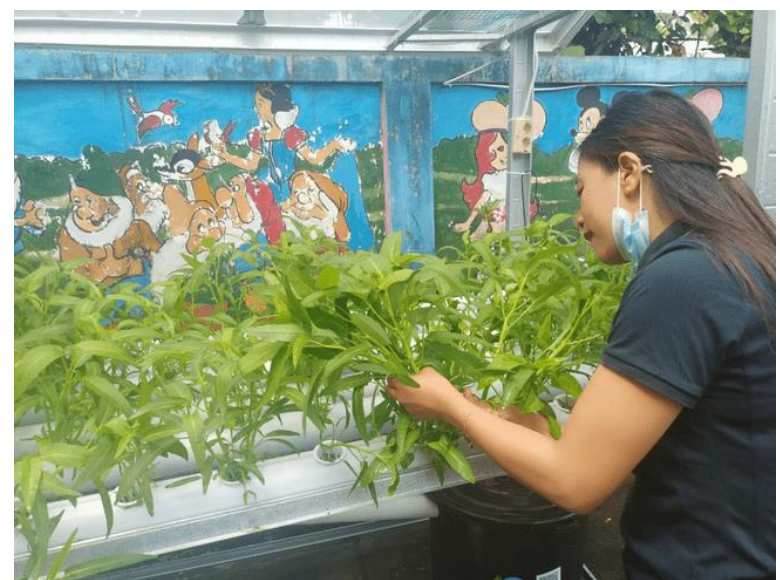

Gambar 8. Hasil panen pertama menanam kangkung

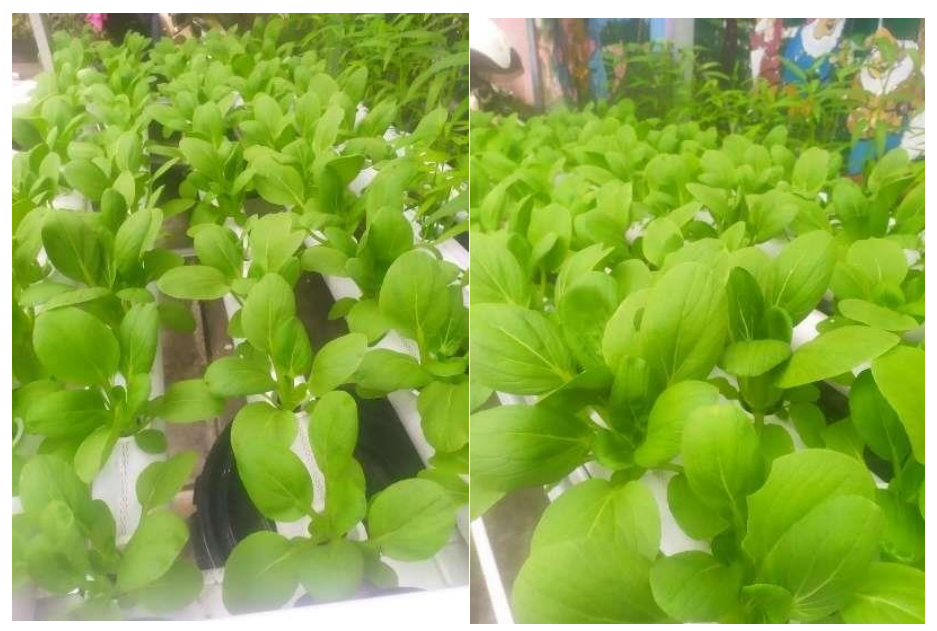

Gambar 9. Hasil panen kedua menanam pakcoy 
Kegiatan evaluasi dilakukan melalui pre-test dan post-test serta melihat hasil pertumbuhan sayuran sampai pada masa panen. Dari hasil alih pengetahuan yang dilakukan, hasil angket menunjukkan bahwa terjadi peningkatan pengetahuan guru tentang budidaya tanaman hidroponik dan pembelajaran matematika permulaan melalui bercocok tanam hidroponik mencapai $90 \%$, evaluasi terkait pertumbuhan tanaman menunjukkan bahwa tanaman hidroponik dapat tumbuh dengan baik.

\section{KESIMPULAN}

Dari kegiatan yang telah dilakukan dapat ditarik simpulan bahwa pelatihan hidroponik pada guru-guru PAUD yang dilakukan mampu meningkatkan pengetahuan dan keterampilan guru dalam bercocok tanam hidroponik. Hal ini ditunjukkan dari kerberhasilan guru dalam melakukan penyemaian, perawatan, hingga panen.

\section{SARAN}

Saran yang dapat diberikan untuk keberlanjutan program adalah perlunya dirancang modul bercocok tanam yang menarik untuk siswa sehingga dapat dijadikan sebagai media belajar yang menyenangkan.

\section{UCAPAN TERIMA KASIH}

Tim penulis mengucapkan terima kasih kepada Lembaga Penelitian dan Pengabdian Masyarakat (LPPM) STMIK STIKOM Indonesia yang telah memfasilitasi kegiatan pengabdian ini sehingga dapat terlaksana dengan baik.

\section{DAFTAR PUSTAKA}

Halim, L., \& I, Y. (2019). Strategi Pelatihan Hidroponik Sebagai Pemberdayaan Masyarakat Yang Bernilai Ekonomis. Patria, 1(2), 69. https://doi.org/10.24167/patria.v1i2.2069

Hartawan, I. N. B., Santika, P. P., Putri, N. W. S., \& I Ketut Setiawan. (2019). Pembuatan Media Interaktif Berbasis Power Point Untuk Guru Sma Dalam Menghadapi Revolusi Industri 4.0. Jurnal Abdi, 6(2), 110-116.

Kemdikbud. (2014). Standar Nasional Pendidikan Anak Usia Dini. Peraturan Menteri Pendidikan Dan Kebudayaan Republik Indonesia, 13.

Nurhikmahyanti, D., Ismawati, R., \& ... (2020). Hidroponik Sebagai Laboratorium Pembelajaran Lingkungan Hidup Anak Usia Dini. Prosiding Seminar ..., (1), 193-196.

Putri, N. W. S., Suryati, N. K., Kartini, K. S., \& ... (2020). Peningkatan Softskill Ict Guru Melalui Pelatihan Penggunaan Microsoft Office Dan Sosial Media. JMM (Jurnal ..., 4(4), 6-9. 